\title{
Myoepithelioma of parotid gland - a diagnosis of immunohistochemistry
}

\author{
Sahai J. ${ }^{1}$, Sahu S. ${ }^{2}$, Hoogar M.B. ${ }^{3}$, Gaikwad P. ${ }^{4}$ \\ ${ }^{1}$ Dr. Jyotsna Sahai, Resident, ${ }^{2}$ Dr. Shilpi Sahu, Professor, ${ }^{3}$ Dr. Hoogar M.B, Associate Professor, ${ }^{4}$ Dr. Priyanka Gaikwad, \\ Resident, all authors are affiliated with the Department of Pathology, MGM Medical College, Navi Mumbai, \\ Maharashtra, India
}

Corresponding Author: Dr. Jyotsna Sahai, Department of Pathology, MGM Medical College, Navi Mumbai, Maharashtra, India. E-mail: jyotisworld@hotmail.com

\begin{abstract}
Myoepitheliomas are rare benign tumours occurring from any secretory system of the body having myoepithelial cells. In the salivary glands they have an occurrence of $1 \%$ with the parotid gland being the most commonly affected gland. The epithelioid variant consists of nests or cords of round to polygonal cells, with centrally located nuclei and a variable amount of eosinophilic cytoplasm. Since this variant is rare and myoepitheliomas can mimic other benign as well as neoplastic conditions, immunohistochemistry is useful for coming to a conclusive diagnosis. We present a case of epithelioid myoepithelioma diagnosed at our institution with the help of immunohistochemistry.
\end{abstract}

Keywords: Myoepithelioma, Salivary Glands, Immunohistochemistry, Histology, Epithelioid.

\section{Introduction}

Myoepithelioma is a benign tumor that can originate from any secretory system throughout the body. In the salivary gland, myoepithelioma is rare, accounting for $1 \%$ of all salivary gland tumors [1].

The overwhelming majority of myoepitheliomas are benign but malignant transformation can take place in recurrent cases and cases left untreated [2,3,4].
Myopeitheliomas are classified into subtypes according to their cell morphology with the spindle cell variant being the most common subtype followed by the plasmacytoid type [5]. The epithelioid cell variant of myoepitheliomas is a rarer variant and here we present a case of epithelioid variant of myoepithelioma occurring in the right parotid gland diagnosed at our institution.

\section{Case Report}

A 60 years old male presented with complaints of a slowly progressive swelling on right side of his face, over the angle of mandible for last 6 years. There was no sudden increase in size of the swelling and it was not associated with pain, increased or decreased salivation, trismus, pain while mastication, ear pain, headache, blurring of vision or facial muscle abnormalities. There was significant social history of 10-pack-year tobacco consumption. The patient presented to the surgery OPD in view of cosmetic complaints.

On inspection, the swelling was oval in shape, measuring $10 \times 6 \mathrm{~cm}$ with a well-demarcated border anteriorly. Posteriorly the swelling extended behind the tragus and was about $6 \mathrm{~cm}$ away from the temporo-mandibular joint, superiorly it extended till the ear lobule and was lifting the lobule. On palpation, it was hard in consistency and there was no cervical lymphadenopathy noted.

On examination of the oral cavity, the parotid duct opening was found normal and no redness was noted. A right superficial parotidectomy was performed, with preservation of the facial nerve and enucleation of the tumor.

Gross features - We received a specimen of right parotidectomy measuring 9.5 × 5 × $4 \mathrm{~cm}$, weighing 100 gm. Its external surface was well encapsulated and congested. Cut section showed solid and papillaroid, grey white, firm tumor measuring $6 \times 5 \mathrm{~cm}$ surrounded by grey white capsule.

Manuscript received: $10^{\text {th }}$ October 2019

Reviewed: $20^{\text {th }}$ October 2019

Author Corrected: $27^{\text {th }}$ October 2019

Accepted for Publication: $31^{\text {st }}$ October 2019

Pathology Update: Tropical Journal of Pathology \& Microbiology Available online at: www.medresearch.in 833 | P a g e 


\section{Case Report}

Microscopic features - $\mathrm{H}$ and $\mathrm{E}$ stained sections revealed a partially encapsulated and fairly circumscribed lesion comprising salivary gland tissue with marked distortion of normal histological architecture. The salivary gland tissue was replaced by an irregular polymorphous mass comprising solid and cystic areas. The cystic areas were lined by degenerated, inconspicuous epithelium which formed multiple, large, blunt papillary structures showing extensive areas of necrosis. At places, solid areas were noted which consisted of densely scattered round to oval cells with ample pale eosinophilic to clear cytoplasm and round mildly pleomorphic nuclei. Also noted were large areas showing trabecular arrangement of small round cells with abundant intervening hyalinised collagenous tissue. Focal areas of dense infiltration by mononuclear inflammatory cells, multiple hypertrophic nerve fibres with no perineural involvement and areas of haemmorhage were noted.
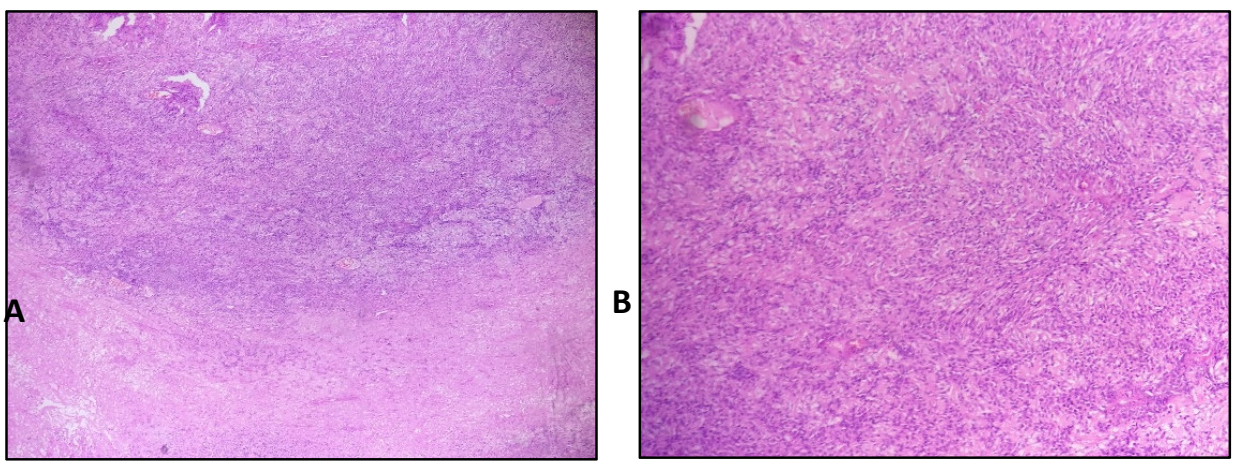

Fig-1 (A): Loss of normal histological architecture of salivary gland (H and $\mathrm{E} \times 4$ ), (B) Solid area with densely scattered cells and fibrocollagenous stroma (H and E x10)

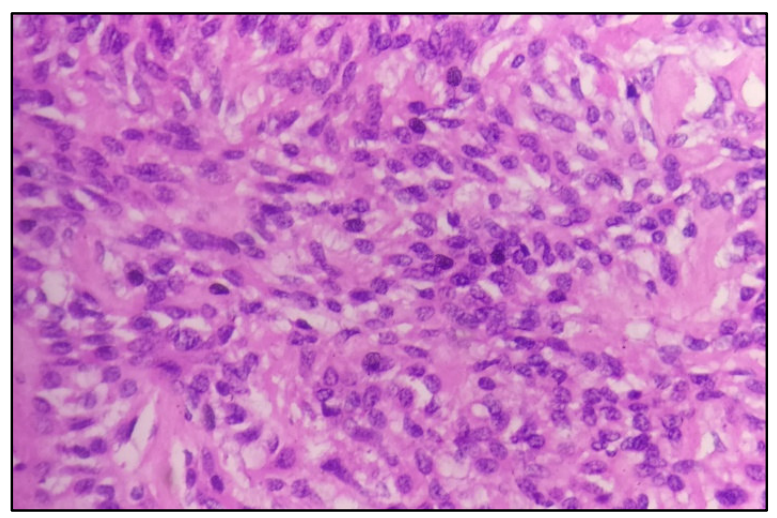

Fig-2: Epithelioid variant of Myoepithelioma showing large polygonal cells with central nuclei and eosinophilic cytoplasm and focal clearing, at places forming pseudo acini / pseudo glandular structures

A diagnosis of Epithelial - Myoepithelial carcinoma was made and immunohistochemistry was done for confirmation of the diagnosis.

A panel of immunohistochemical markers were done which produced the following result:

Table-1: Results of the IHC panel performed.

\begin{tabular}{|c|c|}
\hline Immuno Positive & Immuno Negative \\
\hline CK 7 & CK 5/6 \\
\hline Cytokeratin (AE1/AE3) & CD 117, CD 10 \\
\hline S100 & RCC, TTF - 1 \\
\hline SMA & CEA \\
\hline P63 & Melanosome HMB 45 \\
\hline Calpolin & GFAP \\
\hline MIB -1 & EMA \\
\hline
\end{tabular}

Pathology Update: Tropical Journal of Pathology \& Microbiology Available online at: www.medresearch.in 834 | P a g e 


\section{Case Report}
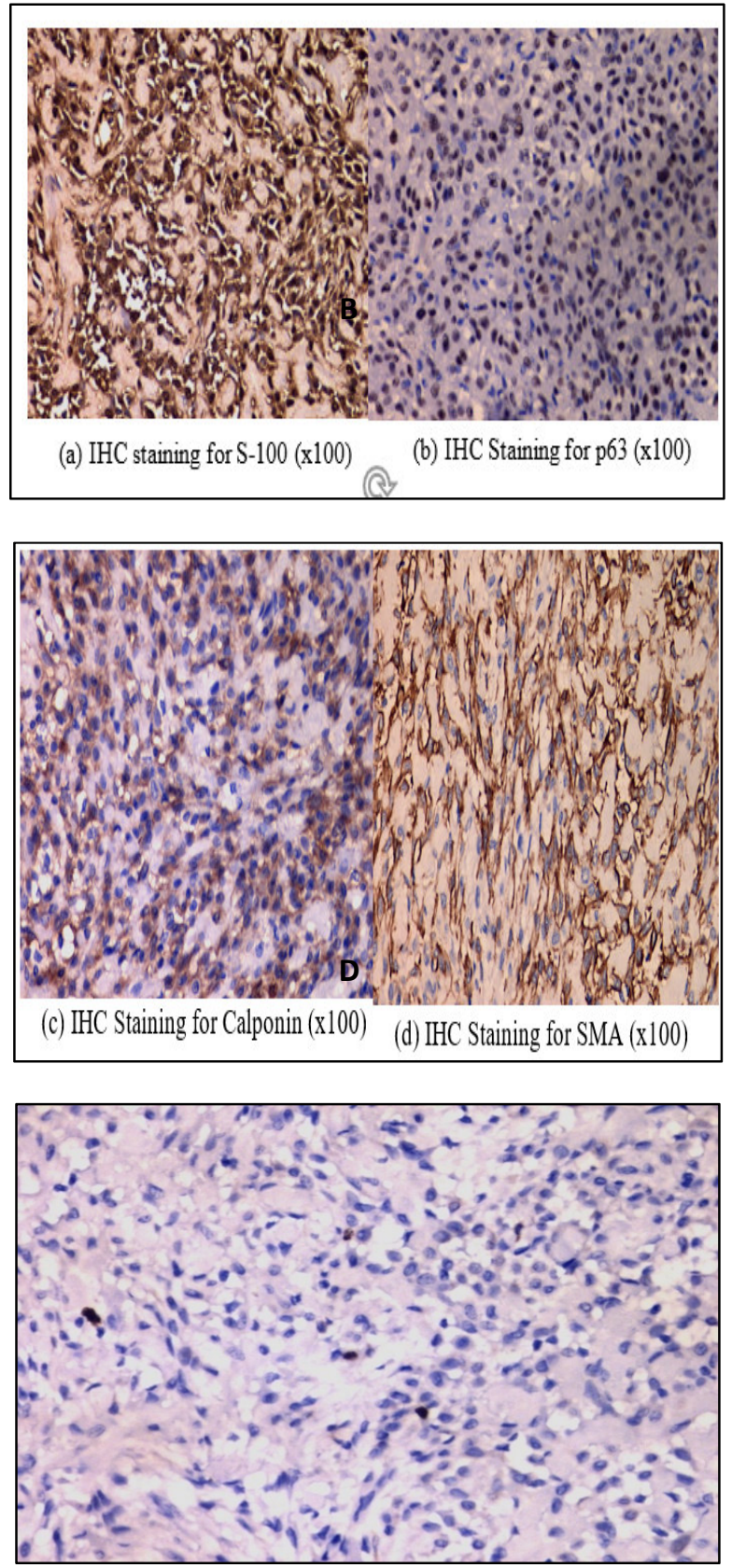

(E) IHC staining for MIB - 1 (x100)

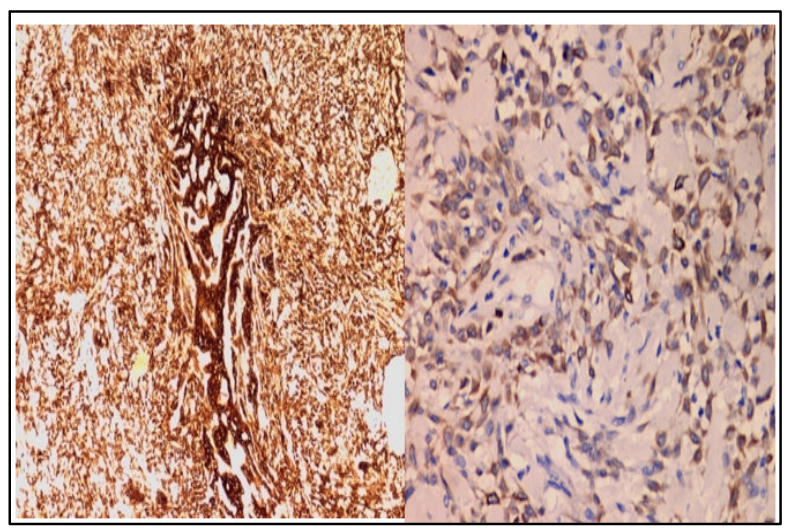

(F) IHC staining for Cytokeratin ( $\mathrm{x} 40, \mathrm{x} 100)$

Fig 3-All positive staining immunohistochemical markers. 


\section{Case Report}

The above mentioned IHC results helped in coming to a definitive diagnosis of Myoepithelioma of the Parotid Gland, which would not have been possible without IHC markers.

\section{Discussion}

The description of a salivary neoplasm resembling a myoepithelioma was first attempted in 1943 [5]. Myoepithelioma of the salivary gland was first officially recognized as a subtype of salivary neoplasms in 1991. [6]. It is a rare benign mass arising from neoplastic myoepithelial or basket cells, which are found between the basement membrane and the basal plasma membrane of acinar cells. They are made up of numerous cellular elements including smooth muscle actin, myosin, and intermediate filaments. Myoepithelial cells are thought to have contractile units that aid in excreting glandular secretions $[2,3]$.

Myoepitheliomas only account for approximately $1 \%$ of all salivary neoplasms [4]. Primarily they will affect the parotid gland $(\sim 40 \%)$ and minor salivary gland sites $(\sim 21 \%)(11)$. Neoplastic myoepithelial cell tumors can be found in nearly all exocrine gland tissues such as skin, soft tissue, sweat glands, breast, lacrimal glands, Bartholin's glands, nasal septum, nasopharynx, larynx, trachea, lung, esophagus, retroperitoneum, and prostate gland. One exception would be the pancreas $[2,7,8]$.

A comprehensive differential diagnosis would include abscess, mucocele, schwannoma, neurofibroma, leiomyoma, benign fibrous histiocytoma, extramedullary plasmacytoma, rhabdomyosarcoma, smooth muscle neoplasms, pleomorphic adenoma, mucoepidermoid carcinoma, myoepithelial carcinoma, and other benign and malignant salivary gland neoplasms [9]. In particular, our case appeared to be cystic in nature. Myoepithelioma tumors have also been misdiagnosed as a parotid cyst [10].

Myoepitheliomas comprise predominant myoepithelial component with epithelioid component being less than $5 \%$ and almost no fibromyxoid stroma. The usual age of presentation is between 40 and 50 years with the spectrum being from 9-85 years of age and it shows a female preponderance of 2:1.

The patients' most commonly present with complaints of a painless mass growing in the mid cheek area with intact facial nerve functions, as was the presentation of the patient in our case. They usually grow locally without invading surrounding structures, such as the facial nerve which is unlike other benign parotid masses [2]. On gross inspection, they usually have a solid, tan or yellow-tan, glistening cut surface. Subtypes of myoepitheliomas are classified by cell morphology: spindle (interlacing fascicles with a stroma-like appearance), plasmacytoid/hyaline (polygonal cells with eccentric nuclei and dense, nongranular or hyaline, abundant eosinophilic cytoplasm), epithelioid (nests or cords of round to polygonal cells, with centrally located nuclei and a variable amount of eosinophilic cytoplasm), and clear (polygonal cells with abundant optically clear cytoplasm, containing large amounts of glycogen but missing mucin or fat) [5]. Of those subtypes, spindle cell type is most common (65\%) followed by plasmacytoid (20\%) [6]. Our case was diagnosed as the epithelioid variant of myoepithelioma.

Due to radiological, histological and cytogenetic similarities, a myoepithelioma can sometimes be misdiagnosed as a pleomorphic adenoma. The most common and shared cytogenic abnormality is seen on chromosome 12q. Immunohistochemical analysis can aid in the diagnosis with immunoreactivity to S-100, cytokeratin (specifically 7 and 14), p63, GFAP, calponin, and myogenic markers (actin, myosin) [5,7]. Except for GFAP, all the other immunohistochemical features were found in our specimen.

The recommended management of myoepithelioma is surgical excision with a margin of uninvolved tissue around. The recurrence rate for myoepitheliomas has been reported to be $15-18 \%$, with possible malignant transformation in long-standing tumors or recurring disease [5]. Malignant transformation has been attributed to the overexpression of c-kit receptors and p53 mutations. Myoepithelial carcinoma can also arise de novo.

Carcinoma only comprises approximately $10 \%$ of all myoepithelial neoplasms [11,12]. Some characteristics of a carcinoma include aggressive behavior (infiltrative and destructive growth), increased mitotic activity, necrosis, lack of myofilaments (therefore more monomorphic than benign myoepithelioma), and cell pleomorphism [3] [5]. As was seen in our case, necrosis and cellular pleomorphism was observed which pointed towards a diagnosis of carcinoma, as was opined upon histological examination.

All these findings and studies prompted an immunohistochemical workup to be done for a definitive diagnosis, which finally helped us reach to the diagnosis of myoepithelioma of parotid gland. This in turn stresses on the fact that immunohistochemistry plays a very important role in reaching a definitive and conclusive opinion and must be done in cases where 


\section{Case Report}

there is a doubt, as it may entirely change the earlier opinion and provide better insight into the diagnosis of the case. This was seen in our case also where it was diagnosed as Epithelial-Myoepithelial carcinoma earlier and mypoeithelioma finally.

\section{Conclusion}

Thus, to conclude, parotid myoepithelioma is a rare diagnosis and must be diagnosed correctly with the help of IHC studies. It must be kept in mind as a differential diagnosis for painless slow growing parotid masses to be able to arrive at a correct diagnosis.

Funding: No funding sources

Conflict of interest: None declared

Ethical Approval: Not Required

\section{References}

1. Kasamatsu A, Shiiba M, Nakashima D, Shimada K, Higo M, Ishigami T, et al. Epithelioid myoepithelioma of the hard palate. Oral Maxillofac Surg. 2013;17 (1): 63-66. doi: 10.1007/s10006-012-0324-y. Epub 2012 Apr 18.

2. Barnes L, Eveson JW, Sidransky D, Reichart P, editors. WHO Classification of tumours. Pathology and genetics of head and neck tumours. $3^{\text {rd }}$ Ed, Volume 9, IARC; 2005.

3. Kermani W, Belcadhi M, Ben Ali M, Sriha B, Bouzouita K. Myoepithelioma of the vallecula: a case report. Ear Nose Throat J. 2011;90(7):E9-E11. doi: 10. 1177/014556131109000720.

4. Iguchi H, Yamada K, Yamane H, Hashimoto S. Epithelioid myoepithelioma of the accessory parotid gland: pathological and magnetic resonance imaging findings. Case Rep Oncol. 2014;7(2):310-315. doi: 10. 1159/000363099.
5. Sheldon W. H. So-called mixed tumours of the salivary glands. Arch Pathol Lab Med. 1943;35:1-20.

6. Seifert G, Brocheriou C, Cardesa A, Eveson JW. WHO International Histological Classification of Tumours. Tentative Histological Classification of Salivary Gland Tumours. Pathol Res Pract. 1990;186 (5):555-581. doi: 10.1016/S0344-0338(11)80220-7.

7. Batsakis JG, Kraemer B, Sciubba JJ. The pathology of head and neck tumors: the myoepithelial cell and its participation in salivary gland neoplasia, Part 17. Head Neck Surg. 1983; 5(3):222-233. doi: 10.1002/hed. 2890050307.

8. Cunha GB, Camurugy TC, Ribeiro TC, Costa NN, Azevedo AC, Vinhaes ES, Andrade NA. Myoepithelioma of the nasal septum: a rare case of extrasalivary gland involvement. Case Rep Otolaryngol. 2017; 2017. doi: 10.1155/2017/7057989.7057989.

9. Oktay M, Yaman H, Belada A, Besir FH, Guclu E. Giant myoepithelioma of the soft palate. Case Rep Otolaryngol. 2014;2014:561259. doi: 10.1155/2014/ 561259. Epub 2014 Mar 3.

10. Kamburoglu HO, Kayikcpoglu AU, Himmetoglu C. A case of myoepithelioma mimicking a parotid cyst. Ear, Nose Throat J. 2015;94(1):37-40.

11. Nayak JV, Molina JT, Smith JC, Branstetter BF 4th, Hunt JL, Snyderman CH. Myoepithelial neoplasia of the submandibular gland: case report and therapeutic considerations. Arch Otolaryngol Head Neck Surg. 2003;129(3):359-62. doi: 10.1001/archotol.129.3.359.

12. Weitzel M, Cohn JE, Spector H. Myoepithelioma of the Parotid Gland: A Case Report with Review of the Literature and Classic Histopathology. Case Rep Otolaryngol. 2017;2017:6036179. doi: 10.1155/2017/ 6036179. Epub 2017 Aug 16.

\section{How to cite this article?}

Sahai J, Sahu S, Hoogar M.B, Gaikwad P. Myoepithelioma of parotid gland - a diagnosis of immunohistochemistry. Trop J Path Micro 2019; 5(10):833-837.doi:10.17511/jopm.2019.110.13. 